\title{
Crescimento e produtividade de inhame e de milho doce em cultivo associado.
}

\author{
Mário Puiattii ${ }^{1}$; Claudenir Fávero ${ }^{2}$; Fernando Luis Finger ${ }^{1}$; Jorge M. Gomes ${ }^{1}$ \\ ${ }^{1 / U F V}$ - Depto. de Fitotecnia; ${ }^{2 / B o l s i s t a ~ d e ~ I C / C N P q ~-~ 36.571-000 ~ V i c ̧ o s a ~-~ M G . ~}$
}

\begin{abstract}
RESUMO
Objetivando avaliar a viabilidade agronômica e econômica da associação inhame e milho doce, foi desenvolvido um trabalho em área da horta de pesquisas da Universidade Federal de Viçosa, em sistema de consórcio (associação aditiva), utilizando-se inhame (Colocasia esculenta) 'Chinês' como cultura principal e milho doce (Zea mays) 'Doce Cristal' como cultura contrastante. O inhame foi plantado em sulcos de $12 \mathrm{~cm}$ de profundidade, no espaçamento de 100 x $30 \mathrm{~cm}$, e o milho doce em covas de $3 \mathrm{~cm}$ de profundidade, na fileira de plantio, entre as plantas de inhame, 40 dias após plantio do inhame. O delineamento experimental foi de blocos ao acaso, com quatro repetições, no esquema fatorial $(3 \times 2)+2$ (três arranjos de plantas: uma planta de milho a cada $30 \mathrm{~cm}$; duas plantas de milho a cada $60 \mathrm{~cm}$ e três plantas de milho a cada $90 \mathrm{~cm}$ x dois manejos das plantas de milho: sem e com corte e retirada da parte aérea das plantas de milho no momento da colheita das espigas verdes + dois controles: monoculturas de inhame e de milho doce). Foram avaliadas características de crescimento e de produção das culturas, além dos índices de eficiência dos consórcios. As duas espécies são adequadas para plantio em sistema de consórcio. O arranjo com uma planta de milho a cada $30 \mathrm{~cm}$ propiciou maiores produtividades e índices de eficiência dos consórcios. Com exceção do arranjo com três plantas de milho/cova a cada $90 \mathrm{~cm}$ com corte da parte aérea das plantas de milho na colheita das espigas, no qual ocorreram menores índices de eficiência dos consórcios e rendimento financeiro total inferior ao da monocultura do inhame, as demais associações estudadas demonstraram-se viáveis agronômica e economicamente.
\end{abstract}

Palavras-chave: Colocasia esculenta, Zea mays, cultivos múltiplos.

\begin{abstract}
Growth and productivity of taro and sweet corn under intercropping conditions.

An experiment was conducted to evaluate some crop production characteristics and economic viability of intercropping systems using taro (Colocasia esculenta) 'Chinês', as major crop, and sweet corn (Zea mays) 'Doce Cristal' as minor crop. Taro corms were planted in 12-cm-deep furrows in a $100 \times 30 \mathrm{~cm}$ spacing. Sweet corn seeds were sowed in the row between the taro plants 40 days after the main crop planting. Corn plants were distributed in three arrays, as follows: one corn plant $30 \mathrm{~cm}$ apart; two corn plants $60 \mathrm{~cm}$ apart, and three corn plants $90 \mathrm{~cm}$ apart; and two growing systems (with and without removing the corn shoot when the ears were harvested at 110 days after sowing - soft kernel stage), comprising six treatments of intergrown and two control treatments (i.e., single crops). The experiments were organized in four random blocks, in a factorial array design $(3 \times 2)+2$ (three distribution of plants: one corn plant $30 \mathrm{~cm}$ apart; two corn plants $60 \mathrm{~cm}$ apart, and three corn plants $90 \mathrm{~cm}$ apart by two systems of corn growth: with and without removal of shoot when the ears were harvested + two control: single crop of either taro or sweet corn). Data for plant growth, production and the efficiency for the different planting systems arrays were collected. Both crops were suitable for intergrowing systems. Higher values for crop production and intergrowing efficiency index were obtained in treatment with one corn plant $30 \mathrm{~cm}$ apart. Lower intergrowing efficiency index and economical return were observed in the treatment where each three corn plants were $90 \mathrm{~cm}$ apart and shoots were removed just after the harvest at the soft kernel stage. The others intercrop systems were both agronomically and economically viable.
\end{abstract}

Keywords: Colocasia esculenta, Zea mays, intercropping.

\section{(Aceito para publicação em 17 de fevereiro de 2.000)}

$\mathrm{O}$ sistemas de cultivos múltiplos constituem-se em peça fundamental na manutenção da pequena propriedade agrícola em países em desenvolvimento ou como componentes de sistemas agrícolas sustentáveis (Vandermeer, 1981; Santos, 1998). O potencial desses sistemas relaciona-se com o aumento da eficiência de exploração dos recursos naturais e do uso da terra, além de conferir proteção contra pragas e doenças e de reduzir a pressão exercida por plantas espontâneas sobre as culturas (Altieri, 1995; Liebman, 1995; Santos, 1998). Outro fator a se destacar é o aspecto social desta práti- ca, uma vez que ao envolver maior utilização de mão-de-obra, normalmente de cunho familiar, funciona como mecanismo de integração de seus membros e da comunidade rural reduzindo o êxodo do campo.

Dentre os sistemas de cultivos múltiplos, o consórcio de plantas, em particular, tem recebido especial atenção, principalmente pela riqueza de suas interações ecológicas e do arranjo e manejo das culturas no campo, o que contrasta com a exploração de sistemas agrícolas sustentados em monoculturas, com uso intensivo de capital e de "insumos modernos" (Santos, 1998). Para a maio- ria dos pequenos proprietários rurais, a preocupação com a produtividade biológica e com o retorno econômico é menor que aquela dispensada ao suprimento de alimentos para a família com mínimo envolvimento de capital e de riscos (Francis, 1986; Santos, 1998).

Dentre as culturas com grande potencial para exploração em sistema de consórcio, tem-se o inhame (Colocasia esculenta), que é alimento básico para diversas populações distribuídas pelo mundo, especialmente nas regiões tropicais e subtropicais úmidas (Wang, 1983; Rubatsky \& Yamaguchi, 1997). Seus rizomas, além de apresentarem boa 
conservação pós-colheita, são fonte de carboidratos, minerais e vitaminas (Hashad et al., 1956; Plucknett et al., 1970; Sunell \& Arditti, 1983; Wang, 1983; Puiatti et al., 1990, 1992; Rubatsky \& Yamaguchi, 1997). Esta espécie é rustica, de fácil cultivo, ciclo longo porém com flexibilidade de colheita, com grande versatilidade quanto às formas de consumo, tolerante ao sombreamento, além de clones com adaptação à condições edafoclimáticas distintas (Plucknett et al., 1970; de la Pena, 1983; Sunell \& Arditti, 1983; Wang, 1983; Nolasco, 1984; Heredia Zarate, 1988, 1995; Rubatsky \& Yamaguchi, 1997). O inhame é uma espécie de regiões tropicais úmidas, apresentando certa tolerância ao sombreamento (Plucknett et al. 1970; de la Pena, 1983; Sunell \& Arditti, 1983; Wang, 1983; Rubatzky \& Yamaguchi, 1997), sendo que em alguns países é tradicionalmente cultivado em consórcio com coco, milho e outras culturas, apesar de poder crescer à luz direta (Rubatzky \& Yamaguchi, 1997). A tolerância ao sombreamento (que pode estar ligada à flexibilidade da arquitetura da planta e à plasticidade na absorção de biomassa), constitui-se em fator chave em determinadas associações, e sua ausência tem sido a causa do insucesso de associações quando do excessivo sombreamento de uma espécie em decorrência do crescimento acentuado de outra (Cruz \& Sinoquet, 1994, citados por Santos, 1998). Por outro lado, o milho doce (Zea mays), é um importante alimento indicado para o consumo humano principalmente como fonte de calorias, além de vitaminas e proteínas (Pereira, 1987; Rubatsky \& Yamaguchi, 1997). Devido ao sabor adocicado, pericarpo fino e endosperma com textura delicada, o milho doce é indicado para consumo humano no estádio de grãos verdes (Pereira, 1987; Parentoni et al., 1990; Rubatsky \& Yamaguchi, 1997; Wolfe et al., 1997). É uma espécie de ciclo relativamente curto, rústica, produtiva (Parentoni et al., 1990, 1991; EMBRAPA, 1992; Rubatsky \& Yamaguchi, 1997), com boa adaptação a grandes amplitudes térmicas (Rubatsky \& Yamaguchi, 1997) e por ser planta $\mathrm{C} 4$, adapta-se melhor a ambientes com alta luz (Wolfe et al., 1997).
No Brasil, seu cultivo poderá se constituir em boa opção para os agricultores visando atender à demanda crescente pelo consumo "in natura" e/ou pela indústria de enlatados (Parentoni et al., 1991). Por apresentar hábito de crescimento e desenvolvimento temporal distintos ao do inhame, constitui-se numa opção bastante interessante para associação com inhame. Essa associação permitiria melhorar a exploração da área, com investimentos reduzidos e retorno financeiro antecipado ao colher as espigas de milho ainda verdes.

Os objetivos do experimento foram verificar a viabilidade agronômica e econômica da associação inhame e milho doce, em três arranjos de plantas e dois manejos das plantas de milho após a colheita das espigas verdes.

\section{MATERIAL E MÉTODOS}

O trabalho foi desenvolvido em área da horta de pesquisas da Universidade Federal de Viçosa (UFV) no período de 05 de setembro de 1988 a 05 de junho de 1989, em solo Podzólico VermelhoAmarelo Câmbico, textura argilosa e topografia plana. As análises realizadas nas amostras de solo, nos Laboratórios de Física e de Química de Solos do Departamento de Solos da UFV, revelaram os seguintes valores: argila $=55$, silte $=$ 19 , areia fina $=9$ e areia grossa $=17$ dag/kg de solo; $\mathrm{pH}$ em água $(1: 2,5)=$ 5,5; $\mathrm{Al}^{+3}=0,1, \mathrm{Ca}^{+2}=3,4 \mathrm{e} \mathrm{Mg}^{+2}=0,9$ $\mathrm{cmol} / \mathrm{dm}^{3} ; \mathrm{P}=88$ e $\mathrm{K}=141 \mathrm{mg} / \mathrm{dm}^{3} \mathrm{de}$ solo e $\mathrm{C}=2,0 \mathrm{dag} / \mathrm{kg}$ de solo.

Foi avaliado o consórcio (associação aditiva) entre as culturas de inhame (cultura principal ou padrão) e de milho doce (cultura contrastante). O inhame foi plantado em sulcos de $12 \mathrm{~cm}$ de profundidade, no espaçamento $100 \times 30 \mathrm{~cm}$. Após a colocação das mudas, no sulco de plantio, foi passado sulcador bico de pato, tração animal, entre as linhas de plantio, cobrindo as mudas de inhame e formando os sulcos de irrigação com profundidade aproximada de $15 \mathrm{~cm}$. O milho doce foi plantado na fileira de plantio do inhame, em covas com cerca de $3 \mathrm{~cm}$ de profundidade, feitas com auxílio de enxada, entre as plantas de inhame, 40 dias após plantio (DAP) do inhame.
O delineamento experimental adotado foi de blocos ao acaso, com quatro repetições, no esquema fatorial ( 3 x 2 ) +2 (três arranjos de plantas: uma planta de milho a cada $30 \mathrm{~cm}$, duas plantas a cada $60 \mathrm{~cm}$ e três plantas a cada $90 \mathrm{~cm}$ $\mathrm{x}$ dois manejos das plantas de milho: sem e com corte e retirada da parte aérea das plantas de milho por ocasião da colheita das espigas verdes + dois controles: monoculturas de inhame e de milho doce). O corte das plantas de milho foi realizado rente ao solo, com auxílio de enxada, e a parte aérea das plantas foi retirada da área experimental imediatamente após a colheita das espigas verdes.

A parcela experimental foi composta de 4 linhas de 3,60 m de comprimento $\left(14,4 \mathrm{~m}^{2}\right)$ e teve como área útil $(3,6$ $\mathrm{m}^{2}$ ) as duas linhas centrais excetuandose $0,90 \mathrm{~m}$ das extremidades. Os dois tratamentos controle (monoculturas de inhame e de milho doce) foram espaçados de 100 x $30 \mathrm{~cm}$ apresentando populações de 33.333 plantas/ha para inhame e para o milho doce. Para cada cultura, essas populações foram mantidas constantes em todos os tratamentos consorciados (associação aditiva); dessa forma, variou-se apenas o arranjo das plantas e o manejo das plantas de milho doce na colheita das espigas verdes.

Para propagação do inhame 'Chinês' foram utilizados rizomas filhos com peso médio de $55 \mathrm{~g}$, obtidos no banco de germoplasma de hortaliças da UFV. Para o milho, foram utilizadas sementes da variedade 'Doce Cristal' adquiridas no comércio, sendo colocadas de três a cinco sementes/cova, procedendo-se o desbaste das plântulas em excesso aos 15 dias após emergência, deixando-se o número de plantas/cova de acordo com cada tratamento. Em razão dos níveis elevados de nutrientes apresentados na análise química do solo não foi realizado nenhum tipo de adubação. Foram realizadas, durante o cultivo, quatro capinas manuais, aos 40, 75, 125 e 185 dias após o plantio (DAP) do inhame. $\mathrm{Na}$ ausência de chuvas, e até 30 dias antes da colheita do inhame, foram realizadas irrigações semanais, por infiltração, nos sulcos formados entre as linhas de plantio, aplicando-se, em cada irrigação, uma lâmina de água de cerca 
de $40 \mathrm{~mm}$, considerada suficiente para atender às necessidades das culturas de inhame (Soares, 1991) e do milho doce (EMBRAPA-CNPMS, 1992).

Durante o desenvolvimento das culturas, seis plantas de inhame previamente escolhidas e identificadas na parcela útil, foram avaliadas mensalmente, a partir de 70 até 250 DAP, quanto a área foliar, a altura de planta e o número de folhas emitidas. Para avaliação da área foliar foi utilizado o método de Chapman (1964), adaptado para o inhame 'Chinês' por Nolasco (1984), utilizando-se da equação $\mathrm{Y}=242,0$. $\mathrm{X}^{0,6656}$. O valor $\mathrm{X}$ utilizado correspondeu ao valor médio das medidas tomadas da última folha emitida com o limbo foliar totalmente expandido das seis plantas identificadas. Para o cálculo do Índice de Área Foliar $\left(\mathrm{L}-\mathrm{dm}^{2} / \mathrm{m}^{2}\right)$, o valor $\mathrm{Y}$ foi multiplicado pelo número médio de folhas fotossinteticamente ativas/planta e pelo número de plantas presentes na área útil da parcela, dividindo-se o valor encontrado pela área útil da parcela $\left(3,6 \mathrm{~m}^{2}\right)$. A altura de plantas foi obtida pela distância da superfície do solo até a inserção do pecíolo no limbo foliar da folha utilizada para medições da área foliar. Considerou-se, para o número de folhas emitidas no intervalo das avaliações, as folhas com o limbo aberto.

Aos nove meses do plantio do inhame, após atingida a maturação, as plantas de inhame foram colhidas e avaliadas quanto a produção de rizomas. Os rizomas mãe foram separados, e os rizomas filhos classificados, com base no diâmetro transversal, de acordo com Puiatti et al. (1990), nas classes extra $=$ filho grande $(>47 \mathrm{~mm})$, especial $=$ filho médio $(40-47 \mathrm{~mm})$, primeira $=$ filho pequeno $(33-40 \mathrm{~mm})$ e refugo $(<33$ $\mathrm{mm})$, contados e pesados. Considerouse produção comercial o somatório das três primeiras classes.

Para o milho doce, aos 90 DAP, foi avaliada a altura de plantas (do nível do solo até o ápice do pendão floral), altura da inserção da primeira espiga e diâmetro do colmo a 1,0 m de altura do nível do solo. Aos 110 DAP do milho (150 DAP do inhame), com as espigas apresentando grãos verdes ("estádio de pamonha"), as plantas tiveram as suas espigas colhidas e avaliadas quanto a produção de espigas com e sem palha (número e peso de espiga).

A Produtivade Relativa da parte colhida de cada Cultura (PRc) foi calculada pela relação entre a produtividade da cultura em associação/produtividade da respectiva cultura solteira (monocultura); o Índice de Eficiência da Terra (IET) consistiu do somatório das PR de cada cultura na respectiva associação: $\mathrm{IET}=\mathrm{PRi}+\mathrm{PRm}$, onde: PRi e $\mathrm{PRm}=$ Produtividades Relativas do inhame (i) e do milho (m). No cálculo do rendimento financeiro considerou-se, para o milho doce, a produtividade total de espigas em palha com valor médio de $\mathrm{R} \$ 5,00 /$ saca de $25 \mathrm{~kg}$ nas Centrais de Abastecimento de Belo Horizonte (CEASA-BH) no mês de fevereiro/ 98 (correspondendo ao mês da colheita do milho). Para o inhame calculou-se o rendimento ponderado, considerando-se o somatório das multiplicações das produtividades de cada classe de inhame pelo respectivo valor médio de comercialização na CEASA-BH, no mês de junho/98 (correspondendo ao mês da colheita do inhame), valendo a saca de $20 \mathrm{~kg}$ : R\$ 3,00, R\$ 11,00, R\$ 8,00 e $\mathrm{R} \$ 4,00$, respectivamente para rizomas mãe, filho grande, filho médio e filho pequeno.

Exceto para os dados de crescimento das plantas de inhame e os índices de eficiência das associações, os quais são apresentados como valores médios sem análise estatística, para os demais dados obtidos foi realizada a análise de variância, e às médias aplicado o teste de Tukey a 5\% de probabilidade. Considerou-se, para efeito de análise estatística do fatorial, apenas observações advindas de cada cultura, conforme Wijesinha et al. (1982). Valores oriundos de contagem foram transformados por $\sqrt{\mathrm{x}+0,5}$ para proceder às análises estatísticas. Os rendimentos financeiros ( $\mathrm{R} \$ / \mathrm{ha}$ ) da monocultura do inhame (controle) e das associações (fatorial) foram comparados pelo teste de Dunett a 5\% de probabilidade.

\section{RESULTADOS E DISCUSSÃO}

Todos os tratamentos em associação afetaram o crescimento da parte aérea das plantas de inhame (Figura 1). No período entre 30 e 90 DAP do milho (70 a 130 DAP do inhame), observou-se,

Tabela 1. Alturas de planta (AP) e de inserção da $1^{\text {a }}$ espiga (AIE), diâmetro de colmo (DC), número de espigas/planta (EP), peso médio de espigas (PME) com e sem palha, número de plantas colhidas $/ \mathrm{m}^{2}$ (PC), produção de espigas/ha (PE) com e sem palha e rendimento financeiro (RF) proporcionado pela cultura do milho 'Doce Cristal' em consórcio com inhame 'Chinês' em função do arranjo das plantas. Viçosa, UFV, 1988-89.

\begin{tabular}{|c|c|c|c|c|c|c|c|c|c|c|}
\hline \multirow{2}{*}{ Arranjo $^{1}$} & \multirow{2}{*}{$\mathrm{AP}(\mathrm{cm})$} & \multirow{2}{*}{$\begin{array}{l}\text { AIE } \\
(\mathrm{cm})\end{array}$} & \multirow{2}{*}{$\begin{array}{l}\mathrm{DC} \\
(\mathrm{cm})\end{array}$} & \multirow{2}{*}{ EP } & \multicolumn{2}{|c|}{ PME (g) } & \multirow{2}{*}{$\mathrm{PC} / \mathrm{m} 2$} & \multicolumn{2}{|c|}{ PE (kg/ha) } & \multirow{2}{*}{$\mathrm{RF}(\mathrm{R} \$ / \mathrm{ha})$} \\
\hline & & & & & C/ palha & S/ palha & & C/ palha & S/ palha & \\
\hline $1 / 30$ & 278,9 & 139,2 & 2,20 & 1,44 & 347,3 & 160,6 & $2,62 \mathrm{a}$ & $13.026 \mathrm{a}$ & 6.039 & $2.605,20 \mathrm{a}$ \\
\hline $2 / 60$ & 279,9 & 139,8 & 2,29 & 1,46 & 356,1 & 169,8 & $2,18 \quad b$ & $11.531 \mathrm{ab}$ & 5.467 & $2.306,10 \quad b$ \\
\hline $3 / 90$ & 275,2 & 139,0 & 2,39 & 1,47 & 350,3 & 162,6 & $2,20 \quad b$ & $11.169 \quad b$ & 5.193 & $2.233,90$ \\
\hline Fatorial & 278,0 & 139,3 & 2,30 & 1,46 & 351,2 & 164,4 & 2,34 & 11.909 & 5.566 & $2.381,73$ \\
\hline Monocultivo & 297,4 & 148,8 & 2,44 & 1,52 & 374,8 & 178,5 & 2,67 & 15.208 & 7.239 & $3.041,60$ \\
\hline CV (\%) & 4,6 & 7,4 & 7,2 & 9,6 & 7,0 & 7,7 & 12,3 & 10,0 & 13,0 & 10,0 \\
\hline
\end{tabular}

*/Dentro de cada fator médias, nas colunas, seguidas da mesma letra não diferem entre si a $5 \%$ de probabilidade pelo teste de Tukey.

$1 / 1 / 30=$ uma planta de milho a cada $30 \mathrm{~cm} ; 2 / 60=$ duas plantas de milho a cada $60 \mathrm{~cm} ; 3 / 90=$ três plantas de milho a cada $90 \mathrm{~cm}$. 
visualmente, crescimento acentuado das plantas de milho, as quais ocasionaram sombreamento progressivo das plantas de inhame nos tratamentos em associação. Apesar da maioria das espécies da família Araceae serem consideradas plantas de sombra (Rubatzky \& Yamaguchi, 1997), o sombreamento das plantas de inhame proporcionado pelas plantas do milho doce, promoveu, nessa fase, o alongamento dos pecíolos das plantas de inhame fazendo com que essas atingissem maior altura de planta, comparado ao cultivo solteiro (Figura 1C); além disso, para a maioria das associações, o sombreamento também promoveu a expansão do limbo foliar das plantas de inhame, visto que observou-se aumento do índice de área foliar (Figura 1A), sem contudo ter ocorrido alteração na taxa de acúmulo de folhas (Figura 1B). Com a colheita das espigas de milho (110 DAP do milho ou 150 DAP do inhame), observou-se nas plantas de inhame dos tratamentos associados, necrose das folhas superiores, possivelmente em razão do aumento repentino na exposição dessas plantas à luz direta; essa necrose levou à diminuição drástica da área foliar das plantas de inhame dessas associações (Figura 1A), além de um atraso na emissão de novas folhas (Figura 1B), mesmo nas associações nas quais as plantas de milho não sofreram corte na colheita das espigas (T1, T2 e T3). Todavia a injúria (necrose) nas folhas foi mais pronunciada nas associações com maior número de plantas de milho/cova e com a remoção da parte aérea das plantas de milho (T5 e T6 - Figura 1), possivelmente em decorrência de um maior sombreamento inicial provocado pelas plantas de milho às plantas de inhame adjacentes.

Pela análise de variância observouse efeito significativo do arranjo de plantas somente para a cultura do milho, em que com uma planta de milho a cada 30 $\mathrm{cm}$ proporcionou maiores número de plantas colhidas $/ \mathrm{m}^{2}$, produção de espigas com palha e rendimento financeiro pela cultura (Tabela 1). O manejo de plantas teve efeito significativo somente sobre a produção de rizomas mãe, cujo valor foi maior quando não se procedeu o corte das plantas de milho na colheita das espigas (Tabela 2). A interação arranjo x manejo foi signifi-

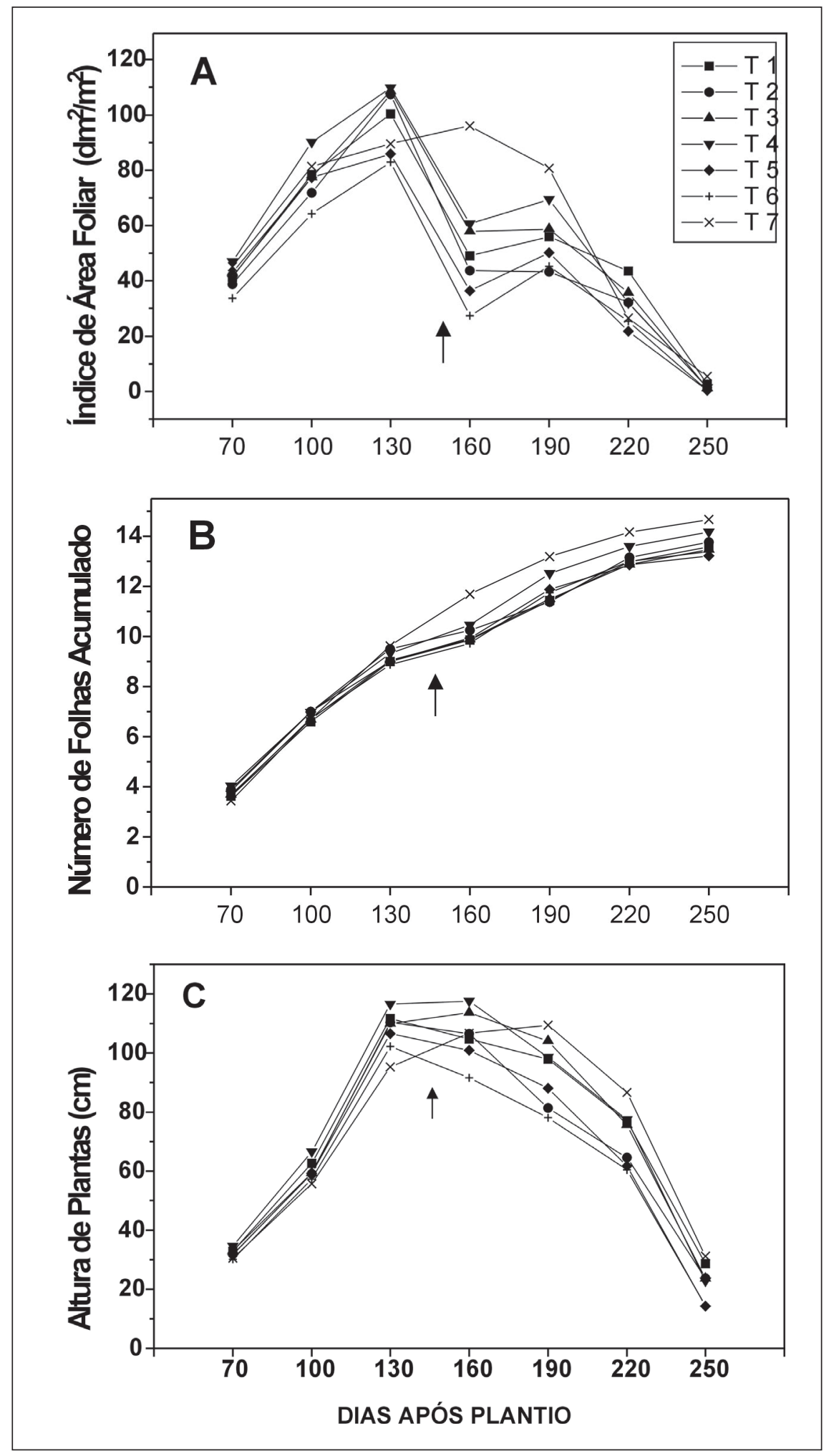

Figura 1. Índice de área foliar (A), número de folhas acumuladas (B) e altura de plantas (C) de inhame 'Chinês' em monocultura e em associação com milho doce 'Doce Cristal', avaliadas entre 70 e 250 dias após o plantio. T1, T2 e T3 correspondem, respectivamente, ao arranjo com uma planta de milho a cada $30 \mathrm{~cm}$, com duas plantas de milho a cada $60 \mathrm{~cm}$ e com três plantas de milho a cada $90 \mathrm{~cm}$, mantendo-se as plantas de milho após a colheita das espigas verdes; T4, T5 e T6, correspondem respectivamente, aos tratamentos T1, T2 e T3, procedendose o corte das plantas de milho e a retirada dessas plantas da aérea de cultivo na colheita das espigas verdes; T7 corresponde à monocultura de inhame. Seta indica a época em que foi realizada a colheita das espigas de milho. Viçosa, UFV, 1988/89. 
Tabela 2. Produção de rizomas mãe (RM), filho grande (FG), filho médio (FM), filho pequeno (FP), comerciais (RC) e total (RT) e rendimento financeiro (RF) proporcionado pela cultura do inhame 'Chinês' em consórcio com milho 'Doce Cristal' em função do arranjo e do manejo das plantas. Viçosa, UFV, 1988-89.

\begin{tabular}{|c|c|c|c|c|c|c|c|}
\hline Arranjo $^{1}$ & RM (kg/ha) & FG (kg/ha) & FM (kg/ha) & FP (kg/ha) & RC (kg/ha) & RT (kg/ha) & RF (R\$/ha) \\
\hline $1 / 30$ & 4.535 & 5.921 & 3.501 & 437 & 9.422 & 14.393 & $5.424,40$ \\
\hline $2 / 60$ & 4.429 & 5.421 & 3.670 & 333 & 9.091 & 13.853 & $5.180,10$ \\
\hline $3 / 90$ & 3.755 & 4.327 & 3.343 & 455 & 7.669 & 11.879 & $4.371,03$ \\
\hline \multicolumn{8}{|l|}{ Manejo $^{2}$} \\
\hline$\overline{\mathrm{S} / \text { corte }}$ & $4.786 \mathrm{a}$ & 5.017 & 3.481 & 395 & 8.498 & 13.679 & $4.948,58$ \\
\hline C/ corte & $3.693 \mathrm{~b}$ & 5.429 & 3.528 & 421 & 8.957 & 13.071 & $5.035,10$ \\
\hline Fatorial & 4.240 & 5.223 & 3.504 & 408 & 8.728 & 13.375 & $4.991,84$ \\
\hline Monocultivo & 5.895 & 9.882 & 4.778 & 665 & 14.600 & 21.160 & $8.330,55$ \\
\hline CV (\%) & 17,4 & 22,7 & 21,0 & 17,1 & 19,9 & 17,3 & 18,6 \\
\hline
\end{tabular}

*/Dentro de cada fator médias, nas colunas, seguidas da mesma letra não diferem entre si a $5 \%$ de probabilidade pelo teste de Tukey. 1/ 1/30 = uma planta de milho a cada $30 \mathrm{~cm} ; 2 / 60=$ duas plantas de milho a cada $60 \mathrm{~cm} ; 3 / 90=$ três plantas de milho a cada $90 \mathrm{~cm}$.

2/ S/ corte = plantas de milho permaneceram até a colheita do inhame; $\mathrm{C} /$ corte $=$ plantas de milho foram cortadas rente ao solo e retiradas da área de cultivo quando da colheita das espigas verdes.

Tabela 3. Rendimento financeiro ( $\mathrm{R} \$ / \mathrm{ha}$ ) das culturas de inhame 'Chinês' e de milho 'Doce Cristal' em associação em função do arranjo e do manejo das plantas. Viçosa, UFV, 1988-89.

\begin{tabular}{ccc}
\hline \multirow{2}{*}{ Arranjo' $^{1}$} & \multicolumn{2}{c}{ Manejo $^{2}$} \\
\cline { 2 - 3 } & S/ corte & C/ corte \\
\hline $1 / 30$ & $7.556,83$ a A & $8.502,40$ a A \\
$2 / 60$ & $7.272,30$ a A & $7.700,50$ a A \\
$3 / 90$ & $7.325,65$ a A & $5.884,20$ b B \\
\hline
\end{tabular}

*/Médias seguidas da mesma letra, minúscula nas colunas e maiúscula nas linhas, não diferem entre si a $5 \%$ de probabilidade pelo teste de Tukey;

1,2/Vide legenda da Tabela 2.

cativa somente para rendimento financeiro das culturas associadas (Tabela 3 ), em que o corte das plantas de milho no arranjo com três plantas de milho a cada $90 \mathrm{~cm}$ proporcionou menor rendimento financeiro. Com exceção para altura de inserção da primeira espiga, diâmetro de colmo e peso médio de espigas, as médias do monocultivo das demais características analisadas, para ambas culturas, foram significativamente superiores às médias do fatorial (Tabelas 1 e 2).

Apesar das plantas de inhame, nas associações, terem apresentado recuperação parcial da parte aérea (após a colheita das espigas do milho) com o decorrer do ciclo, possuindo no final do ciclo índice de área foliar próximo ao do controle (Figura 1A), a produção das classes de rizomas dos tratamentos associados foi afetada de forma significativa em relação à monocultura de inhame (Tabela 2). Em inhame os açúcares solúveis (principalmente os redutores) sintetizados no limbo foliar são translocados para os rizomas (órgãos principais de reserva) passando antes por um "armazenamento temporário" nos pecíolos (Hashad et al., 1956). Dessa forma, o armazenamento de reservas nos rizomas é altamente dependente da integridade das estruturas aéreas (limbo e pecíolo), e qualquer alteração morfofisiológica dessas estruturas poderá afetar a síntese, a quantidade e a velocidade de translocação dos açúcares, repercutindo no crescimento dos rizomas. Danos à parte aérea durante o ciclo podem refletir negativamente na produção de rizomas, uma vez que, conforme observado nos inhames 'Chinês' e 'Japonês', os rizomas filhos iniciam seu crescimento em torno de 165 DAP do inhame (Puiatti et al., 1992), podendo contudo ocorrer variações entre clones e efeito ambiental (Plucknett et al., 1970; Herédia Zarate, 1988, 1995).

$\mathrm{O}$ arranjo com uma planta de milho a cada $30 \mathrm{~cm}$ foi o que menos afetou a produção de rizomas, o qual apresentou, comparativamente aos demais arranjos e à média do fatorial, valores de produção (exceto para filho médio e filho pequeno), rendimento financeiro e PRi numericamente maiores (Tabelas 2 e 4). Por outro lado o arranjo com três plantas de milho a cada $90 \mathrm{~cm}$ proporcionou, exceto para produção de filho pequeno, os menores valores para essas características. Nesse último arranjo as plantas de inhame adjacentes à cova do milho provavelmente tenham sofrido maior competição por fatores de crescimento como luz, água e nutrientes, visto que menores valores de crescimento dessas plantas foram observados durante o ciclo e, em especial, quando procedeu-se o corte das plantas de milho na colheita das espigas (Figura 1). A competição por luz em associações é um dos principais fatores que limita crescimento das culturas associadas, e a maior habilidade de uma cultura em interceptar a radiação fotossintética ativa pode representar uma maior capacidade de explorar nutrientes e água do solo (Harper, 1977).

As culturas podem apresentar mecanismos de compensação da produtividade que podem ocorrer em função de modificações das populações dessas culturas nas associações, bem como nos arranjos espaciais dessas e mesmo em função do sincronismo de plantio e do desenvolvimento temporal das espécies (Santos, 1998). No inhame 'Chinês', foi observada redução do peso da massa do rizoma mãe com aumento da 
densidade populacional (Silva et al., 1971). No presente trabalho a menor produção de rizomas mãe quando do corte da parte aérea das plantas de milho pode ter favorecido o crescimento dos rizomas filhos, embora esse aumento não tenha sido significativo (Tabela 2).

A cultura do milho foi a que mais contribuiu para o IET, apresentando, nos dois fatores em estudo (arranjo e manejo), maiores valores de PR que a cultura do inhame (Tabela 4). Tal fato evidencia que a cultura do milho teve comportamento de cultura dominante (Santos, 1998); por essa razão as associações não interferiram no seu crescimento, expresso pela altura de inserção da primeira espiga, diâmetro de colmo e peso médio de espigas com e sem palha, em que as médias dessas características nos cultivos associados (fatorial) não diferiram de forma significativa das médias do monocultivo (Tabela 1). Em situações de distribuição uniforme dos indivíduos, como ocorre nos arranjos aditivos (caso em questão), a espécie que apresenta crescimento mais rápido sobressai e suplanta a menos vigorosa (Harper, 1977), o que pode ter acontecido com milho em relação ao inhame. Apesar dos fatores em estudo (arranjo e manejo) não terem tido efeito sobre as características de crescimento das plantas e das espigas de milho, o número de plantas de milho colhidas $/ \mathrm{m}^{2}$ e a produção de espigas com palha foram menores nos arranjos com maior número de plantas/ cova (Tabela 1). Isso demonstra que, mesmo sendo cultura dominante, nos arranjos com maior número de indivíduos/cova as plantas de milho sofreram competição em alguma fase do desenvolvimento o que afetou de alguma forma a sua prolificidade. $\mathrm{O}$ milho é uma planta com metabolismo C4, e como tal melhor adaptada a ambientes com alta irradiancia (Wolfe et al., 1997); considerando que seu plantio ocorreu 40 DAP do inhame, as plantas de milho em arranjo com maior número/cova podem ter sofrido competição por luz com a cultura do inhame (e entre si) no estádio inicial de desenvolvimento. A competição por outros fatores e em outras fases de desenvolvimento da cultura, especialmente durante o enchimento dos grãos, quando ambas culturas já apre-

Tabela 4. Produção relativa de rizomas de inhame 'Chinês' (PRi) e de espigas com palha de milho 'Doce Cristal' (PRm) e índice de eficiência da terra (IET) nas associações em função do arranjo e do manejo das plantas. Viçosa, UFV, 1988-89.

\begin{tabular}{llll}
\hline Arranjo $^{1}$ & PRi & PRm & IET \\
\hline $1 / 30$ & 0,68 & 0,86 & 1,54 \\
$2 / 60$ & 0,66 & 0,76 & 1,42 \\
$3 / 90$ & 0,57 & 0,74 & 1,31 \\
\hline Manejo & & & \\
\hline S/ corte & 0,65 & 0,80 & 1,45 \\
C/ corte & 0,62 & 0,77 & 1,39 \\
\hline Fatorial & 0,64 & 0,78 & 1,42 \\
Monocultivo & 1,0 & 1,0 & 1,0 \\
\hline
\end{tabular}

1,2/Vide legenda da Tabela 2.

sentavam os sistemas radiculares desenvolvidos, não deve ser descartada. Interferências negativas entre espécies vegetais nas associações podem estar ligadas a diversos fatores, tais como: competição por recursos como água, nutrientes, $\mathrm{CO}_{2}$ e luz, ou ainda por modificações danosas no microclima e/ou efeitos alelopáticos (Vandermeer, 1981; Santos, 1998), em que a intensidade dessas interações pode ser alterada pelo grau de sincronismo entre o crescimento das espécies envolvidas e o estádio fenológico em que se dá a interferência (Harper, 1977).

Apesar das culturas em associação terem apresentado menores produtividades que as respectivas monoculturas (Tabelas 1 e 2), observa-se pelo IET (Tabela 4), que as associações foram eficientes, uma vez que em todas o IET foi superior a 1,00, indicando que as culturas são adequadas para serem consorciadas (Santos, 1998); ou seja, para que as monoculturas produzissem o mesmo que um hectare das duas culturas juntas haveria a necessidade de área de cultivo total, das duas culturas solteiras, superior a um hectare. Isso evidencia que, de acordo com o "Princípio da Produção Competitiva" de Vandermeer (1981), a competição que ocorreu nessas associações pode ser considerada como do tipo "competição mútua suficientemente fraca", uma vez que, para áreas iguais, as duas culturas em associação produziram mais que as respectivas monoculturas. Esse tipo de resultado é altamente desejável face às limitações que pesam sobre os pequenos agricultores, e demonstra o poten- cial do sistema de cultivo em consórcio para a pequena propriedade agrícola, na qual a limitação de área disponível se torna num dos fatores mais limitantes (Santos, 1998). Observa-se ainda (Tabela 4), que os maiores valores de IET foram alcançados pelo arranjo com uma planta de milho a cada $30 \mathrm{~cm}$, e sem corte da parte aérea das plantas de milho na colheita das espigas, os quais propiciaram as maiores contribuições em termos de produtividade relativa da parte colhida para o inhame (PRi) e para milho (PRm). Além disso, o arranjo com uma planta de milho a cada $30 \mathrm{~cm}$ proporcionou rendimento financeiro pelo milho significativamente superior aos demais arranjos (Tabela 1); comportamento semelhante, embora não significativo, foi observado para o inhame (Tabela 2). Todavia a associação que proporcionou, numericamente, maiores índice de eficiência (IET $=1,55$ ) e rendimento financeiro foi a que envolveu o arranjo de uma planta de milho a cada $30 \mathrm{~cm}$ com o corte das plantas na colheita. Nessa associação o inhame apresentou $72 \%$ do rendimento financeiro proporcionado pela respectiva monocultura de inhame, que somado ao rendimento proporcionado pelo milho (82\% do rendimento proporcionado com a monocultura do milho), alcançou o montante de $\mathrm{R} \$ 8.502,40 /$ ha (Tabela $3)$; destaca-se ainda que o rendimento proporcionado pelo milho ocorreu antecipadamente com a venda das espigas, fato esse que vem demonstrar o potencial dessa associação. A complementariedade ou não-coincidência dos ciclos de crescimento e produção das culturas 
associadas é um dos mecanismos que levam ao sucesso as associações (Santos, 1998), e pode ser o caso dessa associação, inhame com milho doce.

Dentre as associações estudadas, o arranjo com três plantas de milho a cada $90 \mathrm{~cm}$ com corte da parte aérea das plantas de milho na colheita das espigas, foi a menos eficiente (IET $=1,19$ ), e a única que apresentou rendimento financeiro total (inhame + milho) inferior ao da monocultura do inhame (teste de Dunett, $\mathrm{P}<0,05)$ e às demais associações (Tabela 3). O que mais contribuiu para o baixo IET nessa associação foi a pequena PR do inhame $(0,47)$, embora também tenha sido a menor PR alcançada pelo milho $(0,72)$; esses valores podem ter sido devidos a interferências sofridas pelas plantas nessa associação, principalmente pelo inhame, conforme discutido.

A exceção do arranjo com três plantas de milho a cada $90 \mathrm{~cm}$ que apresentou menores valores de PR e IET (Tabela 4) e rendimentos físico e financeiro pelas culturas (Tabelas 1 e 2 ) os demais arranjos apresentaram rendimentos físico e financeiro próximos entre si, destacando-se o arranjo com uma planta de milho a cada $30 \mathrm{~cm}$. O efeito do manejo das plantas de milho na colheita das espigas (sem ou com corte) foi pouco expressivo.

Os resultados obtidos nesse trabalho evidenciam a viabilidade agronômica e econômica das associações de inhame e milho doce. A escolha do tipo de associação deverá levar em consideração as peculiaridades de cada propriedade e a preferência do mercado a comercializar os produtos. Há de se considerar ainda que, nos tratamentos associados, parte do retorno financeiro ocorreu antecipadamente com a venda do milho verde (150 DAP do inhame). Além disso, nas associações com a retirada da parte aérea das plantas de milho ainda verdes teria o opcional de fornecer material vegetal para alimentação animal levando à produção de leite e/ou carne, além do esterco. Esse esterco poderia voltar diretamente à área em cultivos posteriores, ou indiretamente via composto orgânico, repondo, em parte, os nutrientes removidos pelas culturas. Nesses casos, entretanto, deve ser feita uma análise da relação custo/benefício em função do gasto com mãode-obra para execução de tais procedimentos, especialmente na obtenção do composto.

\section{LITERATURA CITADA}

ALTIERI, M.A. Traditional agriculture. In: ALTIERI, M.A. ed. Agroecology: the science of sustainable agriculture. Boulder: Wesview Press, 1995. p. 107 - 144.

CHAPMAN, T. A note on the measurement of leaf area of the tannia (Xanthosoma sagittifolium). Tropical Agriculture, v. 41, n. 4, p. 351 - 352, 1964.

de la PENA, R.S. Agronomy. In: WANG, J.K.; HIGA, S. ed. Taro, a review of Colocasia esculenta, and its potentials. Honolulu: University of Hawaii Press, 1983. p. 167 - 179.

EMBRAPA-CNPMS. EMPRESA BRASILEIRA DE PESQUISA AGROPECUÁRIA - CENTRO NACIONAL DE PESQUISA DE MILHO E SORGO. A cultura do milho doce. Sete Lagoas: EMBRAPA-CNPMS, 1992. 34 p. (Circular Técnica 18).

FRANCIS, C.H. Distribution and importance of multiple cropping. In: FRANCIS, C.H. ed. Multiple cropping. New York: McMillan, 1986. p. 15 - 19.

HARPER, J.H. Population biology of plants. $9 \mathrm{ed}$. San Diego: Academic Press, 1977. 892 p.

HASHAD, M.N.; STINO, K.R.; EL HINNAWY, S.I. Transformation and translocation of carbohydrates in taro plants during growth. Annals of Agricultural Sciences, v. 1, n. 1, p. 261 - 267, June 1956.

HEREDIAZARATE, N.A. Curvas de crescimento de inhame (Colocasia esculenta (L.) Schott) considerando cinco populações, em solo seco e alagado. Viçosa: UFV, 1988.95 p. (Tese doutorado).

HEREDIA ZARATE, N.A. Produção de cinco clones de inhame cultivados no pantanal sulmatogrossense. Horticultura Brasileira, Brasília, v. 13, n. 1, p. 38 - 40, maio 1995.

LIEBMAN, M. Polyculture crop systems. In: ALTIERI, M.A. ed. Agroecology: the science of sustainable agriculture. Boulder: Wesview Press, 1995. p. 205 - 218.

NOLASCO, F. Estudo para o cultivo inundado do inhame (Colocasia esculenta (L.) Schott) em monocultivo e em consórcio com azolla. Viçosa: UFV, 1984. 80 p. (Tese mestrado).

PARENTONI, S.N.; GAMA, E.E.G.; MAGNAVACA, R.; REIFSCHNEIDER, F.J.B.; VILLAS BOAS, G.L. Milho doce. Informe Agropecuário, Belo Horizonte, v. 14, n. 165, p. 17 - 22, 1990.
PARENTONI, S.N.; GAMA, E.E.G.; REIFSCHNEIDER, F.J.B.; GUIMARÃES, P.E.O. Avaliação da capacidade combinatória de dez linhagens de milho doce. Horticultura Brasileira, Brasília, v. 9, n. 2, p. 71 - 73, nov. 1991.

PEREIRA, A.S. Composição, avaliação organoléptica e padrão de qualidade de cultivares de milho-doce. Horticultura Brasileira, Brasília, v. 5, n. 2, p. 22 - 24, nov. 1987.

PLUCKNETT, D.L.; de la PENA, R.S.; OBRERO, F. Taro (Colocasia esculenta), a review. Field Crop Abstracts, v. 23, p. 413 426, 1970.

PUIATTI, M.; GREEMAN, S.; KATSUMOTO, R.; FAVERO, C. Crescimento e absorção de macronutrientes pelo inhame 'Chinês' e 'Japonês'. Horticultura Brasileira, Brasília, v. 10, n. 2, p. $89-92$, nov. 1992.

PUIATTI, M; CAMPOS, J.P. de; CASALI, V.W.D.; CARDOSO, A.A.; CRUZ, R. Sistemas de colocação do bagaço de cana-de-açúcar e do capim gordura, na cultivar de inhame 'Chinês'. Horticultura Brasileira, Brasília, v. 8, n. 1, p. 14 - 16, maio 1990.

RUBATZKY, V.E.; YAMAGUCHI, M. World vegetables. Principles, production, and nutritive values. 2 ed. New York: Chapman \& Hall, 1997. 843 p.

SANTOS, R.H.S. Interações interespecíficas em consórcio de olerícolas. Viçosa: UFV, 1998. 129 p. (Tese doutorado).

SILVA, J.F. da; COUTO, F.A.A.; TIGCHELAAR, E. Efeitos do espaçamento, adubação e tamanho de mudas, na produção do inhame (Colocasia esculenta Schott). Experientiae, Viçosa, v. 12, n. 5, p. 135 - 154, set. 1971.

SOARES, J.G. Crescimento do inhame (Colocasia esculenta (L.) Schott) em duas condições agroclimáticas, em seis níveis de água e cobertura morta. Viçosa: UFV, 1991.91 p. (Tese mestrado).

SUNELL, L.A; ARDITTI, J. Physiology and phytochemistry. In: WANG, J.K.; HIGA, S. ed. Taro, a review of Colocasia esculenta, and its potentials. Honolulu: University of Hawaii Press, 1983. p. 34 - 140.

VANDERMEER, J.H. The interference production principle: an ecological theory for agriculture. Bioscience, v. 31, n. 5, p. 361 364, 1981

WANG, J.K. Introduction. In: WANG, J.K.; HIGA, S. ed. Taro, a review of Colocasia esculenta, and its potentials. Honolulu: University of Hawaii Press, 1983. p. 3 - 13.

WIJESINHA, A.; FEDERER, W.T.; CARVALHO, J.R.P.; PORTES, T.A. Some statistical analyses for a maize and beans intercropping experiment. Crop Science, v. 22, p. 660 - 666, May-June 1982.

WOLFE, D.W.; AZANZA, F.; JUVIK, J.A. Sweet corn. In: WIEN. H.C. ed. The physiology of vegetable crops. New York: CAB International, 1997. p. 461 - 478. 